\title{
La influencia del régimen de la competencia sobre el derecho de los contratos: postulados para una reflexión a partir del sistema francés*
}

\author{
[Artículos]
}

\author{
Joaquín Emilio Acosta Rodríguez ${ }^{* *}$ \\ Mónica Lucía Fernández Muñoz ${ }^{* * *}$
}

Fecha de recepción: 5 de octubre de 2020

Fecha de aprobación: 7 de diciembre de 2020

Citar como:

Acosta Rodríguez, J. E. y Fernández Muñoz, M. L. (2021). La influencia del régimen de la competencia sobre el derecho de los contratos: postulados para una reflexión a partir del sistema francés. Via Inveniendi Et Iudicandi, 16(1). https://doi.org/10.15332/19090528.6477

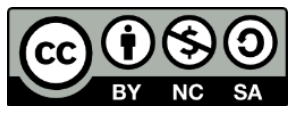

\footnotetext{
* El presente texto es el resultado parcial del proyecto de investigación "La reinterpretación de la teoría de la imprevisión de los contratos a la luz de los principios y valores constitucionales", adscrito al Grupo Derecho, Sociedad y Empresa del Politécnico Grancolombiano, investigación financiada por esta institución universitaria.

** Doctor en Derecho de los Negocios por la Université de Bordeaux (Francia). Magíster en Derecho Privado y especialista en Derecho Comercial por la Université Paris II (Panthéon-Assas). Abogado por la Universidad Santo Tomás (Bogotá, Colombia). Docente e investigador del Programa de Derecho del Politécnico Grancolombiano (Bogotá, Colombia). Correo electrónico: joaquinacosta2001@yahoo.fr, jacosta@poligran.edu.co; ORCID: https://orcid.org/0000-0002-6849-1577

*** Doctora en Persona y Tutelas Jurídicas por la Scuola Superiore Sant'Anna di Pisa (Italia). Especialista en Responsabilidad Civil y Daño Resarcible y en Docencia Universitaria. Abogada por la Universidad del Cauca (Colombia). Docente e investigadora del Programa de Derecho del Politécnico Grancolombiano (Bogotá, Colombia). Correo electrónico: tutorias.mfernandez@gmail.com, mfernand@poligran.edu.co; ORCID: https://orcid.org/0000-0002-7885-8600
} 


\section{Resumen}

Para que una convención sea válida, ya no basta con que ella responda a las exigencias del derecho civil: también es menester que satisfaga las del derecho de la competencia. De esta manera, los acuerdos que falsean el juego de la competencia obligan al juez contemporáneo a alterar la validez de numerosas convenciones, ya que tales comportamientos frecuentemente se apoyan en un acuerdo contractual. Igualmente, la sanción de un abuso de posición dominante puede afectar directamente la formación de un contrato, su renovación en condiciones modificadas e incluso a algunas de sus estipulaciones, si constituyen fruto de tal actitud. En Colombia tal sanción tiene rango constitucional. Las manifestaciones de esta nueva realidad generan múltiples problemáticas; por ende, este artículo aborda la influencia que el derecho de la competencia produce en el derecho de contratos. Se propone un análisis de dicha influencia para reformular el problema de la libertad contractual, a la luz del redimensionamiento del orden público. De esta manera, se recurre a un análisis histórico-originalista, a partir del derecho francés, para repensar la fuerza obligatoria del contrato.

Palabras clave: libertad contractual, derecho de la competencia, orden público económico, orden público.

\section{The influence of the competition regime on contract law: postulates for a reflection based on the French system}

\section{Abstract}

For an agreement to be valid, it is no longer sufficient for it to meet the requirements of civil law: it must also satisfy those of competition law. Thus, the agreements that distort the game of competition oblige the contemporary judge to alter the validity of numerous conventions, since such behaviors are often based on a contractual agreement. Likewise, the penalty for an abuse of a dominant position can directly affect the formation of a contract, its renewal under modified conditions and even 
some of its stipulations, if they are the result of such an attitude. In Colombia, such penalty has constitutional rank. The expressions of this new reality generate multiple problems; therefore, this article addresses the influence that competition law has on contract law. An analysis of this influence is proposed in order to reformulate the problem of freedom of contract, in light of the reshaping of public order. In this way, a historical-originalist analysis, based on French law, is used to rethink the binding force of contract.

Keywords: freedom of contract, competition law, economic public order, public order.

\section{Introducción}

La constatación de que la delimitación clásica de la libertad contractual, también denominada orden público clásico (Gauvain, 2019, p. 40), dejaba de satisfacer los imperativos sociales condujo al legislador a doblar este marco con un orden público económico y social (Farjat, 1963, p. 17; Marque, 1967, p. 522; Hémard, 1950, p. 342; Ripert, 1934, p. 352). Exclusivamente negativo en el pasado, el orden público ha adquirido de esta manera una dimensión positiva. Ya no se contenta con prohibir, sino que impone comportamientos (Terré et ál., 2013, p. 42). De inspiración liberal inicialmente, una mutación profunda se produjo en el siglo XX con la creencia de que el Estado debía orientar la vida económica y contractual también, en una dirección favorable a la utilidad social (Revet, 1996, p. 12; Vargas, 2018, p. 106); de esta manera el Estado debe intervenir en los vínculos contractuales de poderío económico desigual con el fin de proteger a la parte débil (Marque, 1967, p. 520; Malaurie, 1953, p. 162; Ripert, 1934, p. 352; Salah, 1999, p. 261; Savatier, 1965, p. 163). En efecto, inicialmente y en aras de responder a una determinada visión del interés general, el derecho de contratos ha tratado de canalizar la actividad contractual en el sentido que le parece más útil a la colectividad. 
Ya no se trata de proteger una categoría de personas, sino de imponer una particular concepción de la utilidad social. Así, dentro del objetivo de luchar contra la inflación, el Gobierno practica una política de tasación, esto es, fija él mismo el precio de los bienes y servicios. Se habla entonces de orden público económico de dirección (Quiroz, 2014; Saidiza y Carvajal, 2016).

Posteriormente, la doctrina y la jurisprudencia han instado al legislador a reglamentar de manera imperativa el contenido de los contratos celebrados entre partes que se encuentran en una situación de desigualdad estructural, con el fin de evitar que el fuerte explote al débil, más allá de los vínculos laborales: transportista y pasajero, asegurador y asegurado, o arrendador y arrendatario... se habla entonces de orden público económico de protección, fruto de la influencia del derecho del consumo (Flour et ál., 2012, p. 302; Ghestin, 1981, p. 57; Mestre, 1996, p. 33)'. Por razones de metodología, nos centraremos en la primera modalidad ${ }^{2}$.

\section{Problemática}

Para que una convención sea válida, ya no basta que responda a las exigencias del derecho civil: también es menester que satisfaga las del "tentacular" derecho de la competencia (Fages y Mestre, 1998, p. 73; Mestre, 1987, p. 304; Stoffel-Munck, 2000, p. 602). Como lo afirma con fuerte énfasis la Corte de Casación francesa: "son nulas las convenciones que, bajo cualquier forma, y por cualquier causa, tengan por objeto o puedan tener por efecto impedir, restringir o falsear el juego de la competencia" (26 de mayo de 1992) (traducción propia)3. Las

\footnotetext{
${ }^{1}$ Estos autores emplean las expresiones de "ordre public social", "ordre public économique proprement dit", "ordre étatique impératif" y "ordre privé impératif". ${ }^{2}$ En futuros escritos abordaremos la problemática generada a raíz del impacto que ha tenido el derecho del consumo en el derecho de contratos.

${ }^{3}$ Cour de Cassation, Chambre commerciale, du 18 février 1992, 87-12.844, Publié au bulletin: "Sont nulles les conventions sous quelque forme que ce soit, ayant pour objet
}

Via Inveniendi Et Iudicandi

e-ISSN: 1909-0528 | DOI: https://doi.org/10.15332/19090528

Vol. 16 N. ${ }^{\circ} 1$ | enero-junio del 2021 
manifestaciones de esta nueva realidad son múltiples (Garat, 2018, p. 307). Limitándonos a lo esencial, tenemos la prohibición del rechazo a las ofertas de compra (Barret, 2005, p. 5; Corte Constitucional colombiana, Sentencia T-375/97; Serna, 1967, p. 62), así como la de las prácticas discriminatorias, las cuales han propinado golpes serios al principio de la libertad contractual desde hace ya buen tiempo: la primera ha impuesto la celebración de determinados contratos, la segunda ha modelado su contenido (Cañón et ál., 2020). De igual manera, la condena a los acuerdos que falsean el juego de la competencia altera la validez de numerosas convenciones, ya que tales comportamientos suelen apoyarse en una base contractual (Code de commerce, 1807, art. L. 420-1 [Fran.]). Igualmente, la sanción de un abuso de posición dominante puede afectar directamente la formación de un contrato, su renovación en condiciones modificadas e incluso algunas de sus estipulaciones (v.gr. cláusula de exclusividad, cláusula de no competencia) si constituyen fruto de tal actitud (Code de commerce, 1807, art. L. 420-2 [Fran.]). En Colombia, tal sanción tiene rango constitucional (C. P., 1991, art. 333 [Colom.]; Rengifo, 2004, p. 18).

$\mathrm{Al}$ procurar no tanto asegurar el buen funcionamiento del mercado sino, más bien, corregir determinados desequilibrios contractuales, las nuevas reglas son susceptibles de interferir de manera mucho más directa la vida contractual. Son así anulables numerosas estipulaciones contractuales cuya validez parecía, sin embargo, asegurada en virtud de las exigencias tradicionales del derecho de contratos (Mestre, 1994, p. 351). Asimismo, determinado tipo de acuerdos, como los contratos intuitu personae, podrían desaparecer, ya que, al basarse en una elección subjetiva tendiente

ou pouvant avoir pour effet d'empêcher, de restreindre ou de fausser le jeu de la concurrence". Es así nula la cláusula que, en el contrato celebrado entre una petrolera y una bomba de gasolina, prevé que, al expirar ese contrato, la segunda debe restituir en especie a la primera las cubas prestadas, ya que tal pacto busca disuadir la negociación con otros proveedores y constituye así un freno a la competencia.

Via Inveniendi Et Iudicandi

e-ISSN: 1909-0528 | DOI: https://doi.org/10.15332/19090528

Vol. 16 N. ${ }^{\circ} 1$ | enero-junio del 2021 
a excluir a otros participantes económicos, generarían naturalmente un objeto de anticoncurrencial (Oppetit, 1995, p. 251). De seguir fielmente esta vía, el derecho de contratos correría determinados peligros: se arriesgaría a degenerar en un simple instrumento de política económica -socializante ayer, (neo)liberal hoy-. Y el utilitarismo que subyace a estas concepciones solo sería admisible si la ciencia económica tuviera la capacidad de definir un resultado social óptimo, lo cual está lejos de verificarse si se tienen presentes sus frutos pasados (Terré et ál., 2013, p. 428). Igualmente, la desnaturalización de los conceptos jurídicos en nombre de estándares económicos solo puede conducir a la arbitrariedad y a la contingencia de las elecciones (Oppetit, 1992, p. 25).

\section{Una mirada sobre el derecho francés para comprender mejor la problemática colombiana}

Para formular una propuesta que ayude a afrontar tales problemáticas, en lugar de hacer una comparación estricta del derecho de contratos en los regímenes jurídicos colombiano y francés, el eje principal del análisis será el derecho francés. Este sistema será la referencia principal en materia de “concurrencialización” contractual, esto es, la irradiación del régimen de la competencia en el derecho de contratos 4 . A medida que se avance en la temática, ello permitirá aprehender las perspectivas abiertas para el derecho colombiano -y quizás también para otros sistemas jurídicos de la región- en referencia con el derecho francés (Gallego, 2014). En efecto, se estima que el ámbito jurídico colombiano extraerá ingentes beneficios en virtud de tal enfoque. Según los doctrinantes colombianos (Arrubla, 2015 p. 19; Bonivento, 2017, p. 123; Emiliani, 2001, p. 43; Jiménez, 2015, p. 193; Ospina y Ospina, 2018, p. 32), también el estudio del derecho de

\footnotetext{
${ }^{4}$ Concurrencialización es un neologismo, como en su momento ocurrió con el fenómeno de la constitucionalización.
}

Via Inveniendi Et Iudicandi

e-ISSN: 1909-0528 | DOI: https://doi.org/10.15332/19090528

Vol. 16 N. ${ }^{\circ} 1$ | enero-junio del 2021 
obligaciones y contratos se enriquece cuando tiene en cuenta las fuentes de donde emana la organización jurídica nacional (Hourquebie, 2012a, p. 90; Hourquebie, 2012b, p. 41). "Referirse a los orígenes de ese derecho [colombiano] constituye una base de comprensión de sus orientaciones y principios. El derecho civil francés constituye una referencia ineludible para quienes pretenden profundizar la teoría jurídica colombiana" (Cely, 2011, p. 13) (traducción propia). El derecho francés ocupará la mayor parte de este trabajo, lo cual permitirá una mejor comprensión del derecho colombiano, que está fuertemente influenciado por la tradición jurídica francesa. Esta técnica es el "originalismo genealógico": cuando el sentido de un texto es investigado a partir de las fuentes extranjeras que le han inspirado (Le Quinio, 2011, p. 396).

Adicionalmente, en los primeros puestos de los sistemas romanistas figura sin ninguna duda el derecho francés, pionero de la codificación, cuyo modelo ha sido ampliamente difundido no solo en Europa, sino que su influencia se ha extendido a otros sistemas de obediencia romanista, como los derechos de América Latina (Cortabarría, 2005, pp. 1-14; Guzmán, 1994, p. 1361; Guzmán, 2000, p. 13; Guzmán, 2009, p. 19; Larroumet, 2004, p. 8; Mirow, 2000, p. 83; Ramos, 1997).

Así las cosas, comenzaremos el presente abordaje con el denominado orden público económico de dirección.

\section{El orden público económico de dirección}

Este se encuentra conformado por las reglas a través de las cuales el Estado canaliza la actividad contractual en el sentido que le parece más conforme a la utilidad social (Ghestin, 1981, p. 57; Ghestin, 1984, p. 79). De esta manera nace una economía dirigida, practicada en Francia durante unos cuarenta años, especialmente a través de la tasación de los precios y el control de los intercambios (Clamour, 2006, p. 32; Jamin, 2008, p. 17;

Via Inveniendi Et Iudicandi 
Pimont, 2002, p. 41). No obstante, en una economía donde las transacciones internacionales aumentan permanentemente, se verificó que el Estado no podía controlar de manera estable la moneda y los precios, ya que estos solo reconocen las leyes del mercado en un marco de globalización (Arnaud, 2004, p. 53; Basedow, 1999, p. 226; Basedow, 1998, p. 7; Champaud, 2002, p. 171; Delmas-Marty, 2000, p. 402; DelmasMarty, 2001, p. 63; Farjat, 2003, p. 511; Mockle, 2002, pp. 1-7; Ullrich, 2003, p. 311). De ahí un cambio de política económica con la adopción de la Ordonnance 86-1243, del 1 de diciembre de 1986, relativa a la libertad de los precios y la competencia. En adelante, salvo disposiciones particulares, los precios son libremente determinados por el juego de la competencia. De esta manera, el orden público económico de dirección, de inspiración socializante, cede el puesto a un orden público económico de inspiración neoliberal (Terré et ál., 2013, p. 427).

A ello se añaden en Francia nuevas disposiciones que han sido introducidas por la reforma a su derecho de la competencia efectuada por las Loi 96-588, Loi 2001-420 (ley nouvelles régulations économiques [NRE]) y la Loi 2008-776 (modernisation de l'économie) y que figuran en el article L. 442-6 del Code de commerce. En síntesis, la parte esencial del orden público económico de dirección vuelve hoy al derecho de la competencia, cuya importancia no deja de crecer (Dreifuss-Netter, 1990, p. 375; Vogel, 1998, p. 62).

\section{Necesidad de limitar la libertad de comercio e industria}

El liberalismo económico clásico predicó que el principio de la libertad de comercio e industria exige abstenerse de proferir una reglamentación de la competencia. En efecto, los comerciantes mediocres deberían ser eliminados por el libre juego de las reglas del mercado, ya que los clientes tratan con quien vende menos caro al tiempo que ofrece los productos de 
mejor calidad (Echeverry y Díaz, 2016). No obstante, este punto de vista sigue siendo utópico (Auguet, 2002, p. 34; Azéma, 1990, p. 32; BoutardLabarde y Canivet, 1994, p. 53; De Leyssac y Parleani, 2002, p. 71; Decocq y Decocq, 2002, p. 81; Decocq y Decocq, 2010, p. 63; Malaurie-Vignal, 1996, p. 71). De un lado, la transparencia del mercado, condición esencial de la competencia, existe raramente. A pesar de la estandarización jurídica, la competencia relativa a la calidad de los productos juega difícilmente. Únicamente los compradores profesionales están en condiciones de comparar esta calidad. La competencia sobre los precios opera con mayor facilidad, pero el cliente no conoce siempre todos los precios implementados en un momento dado en el mercado. El derecho debe entonces intervenir para permitir que la competencia se materialice. Por otra parte, la experiencia demuestra que una competencia absolutamente libre termina por destruirse a sí misma, ya que de eliminaciones en eliminaciones desemboca en la creación de monopolios. Es necesario que la libertad beneficie a todos y no solamente a algunos. Además, no es siempre el mejor quien gana, ya que como se decía coloquialmente "ley del zorro libre en el gallinero libre es generadora de desorden e injusticias" (Guyon, 2003, p. 909). Contrariamente al sueño de los economistas liberales, la competencia no es un estado natural, espontáneo y normal (Ruet, 2002, p. 3086). Bien al contrario, una economía de competencia no es una economía de facilidad. Ella obliga a los agentes económicos a innovar, así como a mejorar la calidad de sus productos y servicios, en lugar de vivir en la quietud de un coto. También obliga a los comerciantes a vender menos caro y a proponer servicios más apropiados a las necesidades de la clientela. La competencia incita a los consumidores a mostrarse diligentes si pretenden mantener su presión sobre el mercado en aras de mejorar su poder de compra y su calidad de vida. No obstante, la competencia generalmente ni se desea ni se acepta 
por aquellos con estrechez de miras. En consecuencia, ella es casi tan vulnerable y excepcional como los regímenes democráticos. Su libre juego debe ser asegurado por la intervención de las autoridades administrativas y judiciales. Se puede así decir, como el célebre político revolucionario francés Louis Antoine de Saint-Just, "pas de liberté pour les ennemis de la liberté" ('ninguna libertad para los enemigos de la libertad'). Clásicamente esta intervención tuvo por objeto la defensa de la lealtad de la competencia, ya que en la guerra comercial todos los golpes no están autorizados. El derecho de hacer competencia es susceptible de abuso (Schaeffer, 1981, p. 403).

\section{Nota histórica}

A finales del siglo XIX se verificó, especialmente en los Estados Unidos, que la reglamentación comercial en vigor no era suficiente. La Sherman Act de 1890 y posteriormente la Clayton Act de 1914 establecieron las bases de una legislación antitrust, la cual se desarrolló rápidamente (Farjat, 1963, p. 56). El mismo movimiento se produjo mucho más tarde en Francia, ya que durante mucho tiempo el régimen galo se limitó a prohibir las prácticas anticompetitivas individuales. Excepcionales en el siglo XIX, tales prohibiciones se volvieron cada vez más numerosas bajo la influencia de un intervencionismo administrativo creciente - fruto de las dificultades del periodo de guerras mundiales (Ordonnance 45-1483)-, pero que no había desaparecido con el regreso de la prosperidad (Loi 731193). Su aplicación era de la competencia de la rama jurisdiccional.

Sin embargo, a partir de 1953, en Francia la evolución económica condujo a luchar también contra las prácticas contra la competencia denominadas colectivas (Décret 53-707), es decir las ententes. La aplicación de esta nueva reglamentación fue confiada, en lo esencial, a un organismo administrativo, la Commission technique des ententes y, luego de la ley, la 
Commission de la concurrence (Champaud, 1985, p. 61). Sin embargo, esos organismos solo tenían un poder consultivo. La decisión era tomada inicialmente por los tribunales represivos, por cuanto las infracciones a la competencia constituían delitos; posteriormente, a partir de 1977 en Francia, la medida correspondió al ministro de Economía, a quien se confirió el poder de infligir sanciones pecuniarias. Estas multas podían ser objeto de un recurso ante el Conseil d'État, de tal suerte que el derecho de la competencia tenía un aspecto administrativo (Guyon, 2003, p. 927).

La distinción de los comportamientos anticompetitivos individuales de los colectivos presentaba numerosos inconvenientes. Así los abusos de posición dominante estaban considerados como comportamientos colectivos, mientras que son por naturaleza individuales, ya que son cometidos por empresas en situación de monopolio. Adicionalmente, numerosos comportamientos anticompetitivos, especialmente las cláusulas de exclusividad, podían ser casos individuales o colectivos y dar lugar, en consecuencia, a apreciaciones divergentes por el Conseil d'État (Consejo de Estado) y la Cour de cassation (Corte de Casación). De esta manera, la Ordonnance 86-1243, la cual recopiló en Francia la totalidad de las reglas del derecho de la competencia, abandona a justo título la distinción entre comportamientos individuales y colectivos, además efectuó una unificación de los litigios, puesto que tales procesos son en adelante de la competencia de los jueces (Ordonnance 86-1243, modificada por la Loi 87-499, arts. L 464-1 y 464-7). Esta medida solo aumentaría la congestión judicial en Colombia; quizás en nuestro país convenga, a la inversa, dejar tales pleitos en manos exclusivas de la Superintendencia de Industria y Comercio. Esta Ordonnance se basa en otra distinción, inspirada de los derechos estadounidense y comunitario europeo (Bonassies, 1983, p. 56). Tal diferenciación considera que determinados comportamientos son anticompetitivos debido a su 
naturaleza misma, mientras que otros solo se vuelven anticompetitivos en virtud de las vulneraciones que generan al buen funcionamiento del mercado (Vogel, 1994, p. 3746).

La Ordonnance 86-1243 ha sido incorporada al Code de commerce, constituyendo así su livre quatrième ('libro IV'). La Loi 2001-420 aportó algunas modificaciones. Adicionalmente, desde el Reglamento comunitario 1/2003, el juez, así como la autoridad administrativa de la competencia, pueden aplicar directamente el derecho comunitario de la competencia. Más recientemente, la Ordonnance 2019-359 reformó radicalmente el título IV del libro IV del Code de commerce, especialmente en lo relativo a la transparencia mercantil, las prácticas restrictivas de la competencia y demás prácticas comerciales prohibidas.

\section{Derecho de la competencia y derecho de contratos}

Si bien se ha sostenido que el derecho de la competencia tiende a convertirse en una rama autónoma, cada vez más diferenciada del derecho común de obligaciones (Robichez, 1999, p. 176), y que las relaciones contractuales escapan al derecho de la competencia (Burst, 1993, p. 48; Corte de Casación francesa, 22 de octubre de 1985), los acontecimientos ya evocados demuestran otra realidad. Así, restablecer un clima favorable a la libertad contractual es también procurar que exista una verdadera competencia entre los actores de la vida económica, de tal suerte que la ley de la oferta y la demanda pueda funcionar plenamente (Bonassies, 1983, p. 56; Dreifuss-Netter, 1990, p. 375; Malaurie-Vignal, 1995, p. 54; Oppetit, 1995, p. 251; Chagny, 2004, p. 142). La idea no era extraña a los codificadores napoleónicos, quienes, no contentos con afirmar solemnemente el principio de la libertad de comercio e industria también sancionaron penalmente las coaliciones constituidas para procurarse un beneficio económico que no sería el resultado del desarrollo natural de la 
oferta y la demanda (Código Penal francés, 1810, art. 419; Ordonnance 861243, art. 52-1). Sin embargo, tales textos se revelaron ineficaces frente al movimiento de concentración industrial y comercial que modificó profundamente el paisaje económico a partir de finales del siglo XIX (Pfister, 2012, p. 355).

\section{La libertad de competencia, un principio limitado}

La libertad de la competencia presenta múltiples beneficios: favorece la baja de precios y la mejora de la calidad, también permite la aparición en el mercado de productos nuevos y aumenta la diversidad de ofertas (Guyon, 1995, p. 19). En consecuencia, un comerciante no tiene derecho a reparación si su clientela lo abandona para beneficio de un competidor mejor equipado o aprovisionado, que al tiempo venda a mejor precio. Tal competencia es sana. Así, el derecho no debe impedirla.

En Francia, el principio de la libertad de la competencia figura expresamente en el título primero del libro IV del Code de commerce (1807, art. L 410-2 [Fran.]). En consecuencia, nadie cuestiona su existencia, además tal normativa se entiende como una aplicación particular de una libertad más amplia: la de comercio e industria, la cual en Francia observa un valor "cuasi constitucional":

[...] que la liberté qui, aux termes de l'article 4 de la Déclaration, consiste à pouvoir faire tout ce qui ne nu t pas à autrui, ne saurait ellemême être préservée si des restrictions arbitraires ou abusives étaient apportées à la liberté d'entreprendre. (Consejo Constitucional francés, Sentencia 81-132 DC, 16 de enero de 1982)

Reste à savoir si la liberté d'entreprendre se confond avec la liberté du commerce et de l'industrie ou en est distincte. La violation de la liberté du commerce et de l'industrie a été invoquée dans la décision 81-129 DC des 30-31 octobre 1981; mais le Conseil constitutionnel n'a pas 
véritablement répondu à ce moyen et il est donc difficile d'affirmer qu'il a reconnu valeur constitutionnel à cette liberté. Une manière de résoudre le problème est de considérer que la liberté du commerce et de l'industrie comporte deux aspects ou principes : celui de la libre entreprise et celui de la libre concurrence; et de considérer alors que le premier principe a été constitutionnalisé (par les Décis. 16 janv. et 27 juill. 1982) et qu'il n'est pas certain qu'il en ait été de même du second. (Favoreu, 2014, p. 937)

En lo que se refiere al caso colombiano, la Sentencia C-228 de 2010 no deja margen de duda: esta libertad tiene rango constitucional. Este principio significa que toda maniobra que no esté prohibida se entenderá permitida, y así la clientela de un comerciante será el resultado de su habilidad para atraerla, así como su diligencia para conservarla (Champalaune, 2001 p. 8; Goldman, 1992 p. 101; Guyon, 1978, p. 5; Kdhir, 1994, p. 30; Pédamon, 1983, p. 13). En consecuencia, el perjuicio provocado por una competencia leal es lícito y no da pie al derecho a reparación. De esta manera, el simple hecho de vender menos caro que los otros comerciantes no constituye competencia desleal sino una práctica perfectamente sana, bajo reserva de respetar la prohibición de las ventas a pérdida y de jamás procurar, mediante una acción concertada, eliminar a los competidores. Igualmente, esta libertad postula que todo comerciante puede ser "lealmente desafiado" por otro comerciante, quien también puede instalarse en las cercanías de su rival. La Cour de cassation lo ha recordado particularmente a propósito de un peluquero que abrió un salón cerca de su antiguo jefe y atrajo a algunos de sus clientes (Corte de Casación francesa, 16 de octubre de 1972). El Tribunal señala, por un lado, que ninguna regulación prohíbe la apertura de un salón de peluquería en las proximidades de otro y, por otro lado, que el trabajador no había contraído ninguna obligación de no competencia al momento del perfeccionamiento de su contrato de trabajo. De esto deduce que la 
competencia es justa, la persona interesada simplemente aprovecha la experiencia adquirida de su jefe. Finalmente, el alto tribunal desestima el reclamo por daños del exjefe del peluquero (véase también Corte de Casación francesa, 17 de abril de 1980, a propósito de una sala de cine perjudicada por una cafetería que había instalado un receptor de televisión en su establecimiento).

\section{De la restricción de la libertad de la competencia a la restricción de la libertad contractual}

La doctrina reconoce que tal especialidad jurídica, "pieza esencial de un orden público neoliberal” (Terré et ál., 2013, p. 45) (traducción propia), apunta directamente al mantenimiento de la competencia. Sin embargo, aunque en principio libre, la competencia no permite el uso de cualquier procedimiento. No obstante, no existe una lista legal taxativa de actos prohibidos. Es por referencia a los principios fundamentales de responsabilidad civil que los tribunales han desarrollado una teoría de la competencia desleal como "actos contrarios a los usos practicados en círculos comerciales honestos" (Guyon, 2003, p. 911) (traducción propia). En efecto, si bien la competencia es libre, encuentra su límite fundamental en el marco de la lealtad. Ahora bien, la competencia desleal clásica supone que un comerciante utiliza procedimientos abusivos para desviar o tratar de desviar a los clientes de otro comerciante que ejerce su actividad en el mismo campo que aquel (Schmidt-Szalewski, 2003, p. 933). De esta manera, la competencia puede prohibirse excepcionalmente mediante ley o acuerdo. Este es particularmente el caso de los monopolios operativos reconocidos por la autoridad de propiedad intelectual (patentes de invención, marcas registradas). En tal caso, es la competencia misma la que es ilícita, incluso si el procedimiento utilizado es correcto, justo y regular (Pollaud-Dulian, 1999, p. 83). 


\section{Cláusulas de no competencia}

Obviamente, la forma más radical de protegerse de la competencia es evitar la instalación de cualquier competidor (Auguet, 2000, p. 114; Serra, 1998, p. 9). Las cláusulas de exclusividad constituyen un ejemplo de estas prácticas. De hecho, estas permiten una distribución comercial más segura y más eficiente. Sin embargo, tales cláusulas también pueden afectar la libre competencia. Por lo tanto, los acuerdos de no competencia plantean varios interrogantes, si adoptan la forma de una exclusividad de reventa o una exclusividad de compra, generalmente en el marco de un contrato de concesión.

El contrato de concesión es relativamente nuevo en el derecho comercial. Hasta hace unos cincuenta años apenas existía, excepto en el derecho administrativo, donde generalmente se asimilaba a un arrendamiento: el concesionario era el que tenía derecho a usar parte del dominio público. Por el contrario, la concesión comercial es una variedad de venta comercial. Es un contrato innominado, nacido de las necesidades de la práctica y que en el fondo aún no está sujeto a ninguna regulación específica. (Le Tourneau, 1994, p. 72) (traducción propia)

Se discute la conveniencia de una intervención del legislador. Es cierto que tal regulación puede proteger al concesionario contra las cláusulas leoninas, insertadas a veces en el contrato por un licenciante económicamente más poderoso. También pueden evitarse ciertos efectos anticompetitivos de las concesiones exclusivas. Pero un estatuto legislativo tendría la desventaja de la rigidez en un área donde la flexibilidad es necesaria para adaptar rápidamente las redes de ventas a la evolución de las necesidades de los clientes. Además, el derecho común de obligaciones ya protege al concesionario contra maniobras o abuso por parte del concedente. Por lo tanto, la regulación no es necesaria (Maymon-Goutaloy, 1982, p. 520). 
Las cláusulas de no competencia se utilizan en todas las actividades económicas. Así, un médico que reemplaza temporalmente a otro generalmente acepta abstenerse de establecerse en las cercanías durante un cierto periodo para no hacerse con la clientela a la que trató durante su reemplazo. Del mismo modo, el miembro de una profesión liberal que transfiere a su clientela, en la medida en que esta transferencia es legal, también contrae un compromiso de no recuperación dentro de un perímetro y durante un periodo determinados. Estas cláusulas son especialmente frecuentes en las relaciones comerciales. A veces vinculan a dos comerciantes (obligación de no reincorporación de un vendedor de buena voluntad), a veces se aplican en las relaciones de un comerciante y uno de sus antiguos empleados (obligación de no crear un fondo competidor o incluso no contratar con un competidor). A veces, vinculan al arrendador del edificio con el operador del fondo de comercio (compromiso de no alquilar una oficina en el mismo edificio a un competidor, Corte de Casación francesa, 16 de marzo de 1976). A veces, finalmente, figuran en los estatutos de una sociedad (Guyon, 2000, p. 103) o en un contrato, como la venta de un inmueble (Cros, 2002, p. 908).

\section{Validez de las cláusulas de no competencia*}

El derecho positivo francés adopta una posición matizada con respecto a estas cláusulas (Guyon, 2003, p. 928). En efecto, a veces son legítimas, en particular porque especifican el contenido de una obligación legal, como en el caso de la venta de un fondo de comercio (Corte de Casación francesa, 14 de abril de 1992). Pero, a veces, también obstruyen artificialmente una competencia sana en sí misma -socavando así la

\footnotetext{
* Nos limitaremos aquí a las cláusulas pactadas en las relaciones comerciales individuales. Pero también sucede que estas cláusulas resultan del comportamiento anticompetitivo colectivo o son impuestas por una empresa dominante. Por lo tanto, su validez debe evaluarse a la luz del régimen aplicable a este tipo de acuerdos.
}

Via Inveniendi Et Iudicandi

e-ISSN: 1909-0528 | DOI: https://doi.org/10.15332/19090528

Vol. 16 N.o 1 | enero-junio del 2021 
libertad económica-, que es solo un aspecto de la libertad individual (Favoreu, 2014, p. 922). En consecuencia, el legislador francés rara vez prohíbe las cláusulas de no competencia (Décret 91-1197, art. 133, para el caso de los contratos de colaboración entre abogados). Por su parte, los tribunales franceses juzgan que una prohibición contractual de la competencia, es decir, una obligación de no competir, es válida solo si se cumplen dos tipos de condiciones: 1) la libertad de comercio solo puede ser enajenada en beneficio de un tercero que tenga un interés legítimo (Corte de Casación francesa, 8 de mayo de 1967). De esta manera la cláusula será válida si esta tiene como objetivo evitar una competencia anormal o peligrosa. En consecuencia, la cláusula solo es válida si la obligación de no competencia es necesaria para proteger los intereses de su beneficiario (Corte de Casación francesa, 4 de mayo de 1993, y 4 de enero de 1994); 2) la cláusula de no competencia solo puede restringir no suprimir la libertad de acción de su deudor. Por lo tanto, debe limitarse en cuanto a su objeto, es decir, no impedir ninguna actividad económica o profesional, sino solo una actividad relacionada con la realizada por el beneficiario (Corte de Casación francesa, 27 de junio de 1984). Aquí encontramos la idea del interés legítimo, porque si el individuo es totalmente diferente no hay competencia. Asimismo, la prohibición debe limitarse en el tiempo o en el espacio. El alcance exacto de tal limitación es una cuestión de hecho (Corte de Casación francesa, 28 de febrero de 1865; Corte de Casación francesa, 27 de octubre de 1981).

\section{Conclusiones: deslealtad como violación de usos profesionales}

Una revisión de la jurisprudencia y doctrinas francesas conduce a un hallazgo quíntuple en la materia (Corte de Casación francesa, 3 de febrero de 1909; Corte de Casación francesa, 7 de diciembre de 1954; Corte de Casación francesa, 5 de enero de 1966; Corte de Casación francesa, 19 de 
julio de 1976; Corte de Casación francesa, 28 de abril de 1980; Corte de Casación francesa, 5 de octubre de 1982; Corte de Casación francesa, 15 de junio de 1983; Corte de Casación francesa, 30 de noviembre de 1983; Tribunal de Gran Instancia de Grenoble, 3 de mayo de 1984; Corte de Casación francesa, 14 de mayo de 1985; Corte de Casación francesa, 11 de octubre de 1988; Corte de Casación francesa, 29 de marzo de 1989; Tribunal de París, 11 de octubre de 1990; Corte de Casación francesa, 18 de mayo de 1993; Tribunal de Douai, 2 de octubre de 1995; Corte de Casación francesa, 18 de junio de 1996; Corte de Casación francesa, 13 de mayo de 1997; Corte de Casación francesa, 1 de junio de 1999; Corte de Casación francesa, 19 de noviembre de 2002, competencia desleal entre taxis y ambulancias; Consejo de Estado francés, 31 de mayo de 2006; Consejo Constitucional francés, Sentencia 2018-771 DC).

1. En el concepto clásico de competencia desleal, la falta siempre la comete un comerciante que actúa en el mismo sector de actividad que su víctima.

2. La acción en competencia desleal supone una falta (Corte de Casación francesa, 3 de enero de 1985). Sin embargo, la jurisprudencia es algo confusa a este respecto. Algunas decisiones parecen admitir una responsabilidad objetiva. En realidad, se han emitido en caso de infracción de un derecho de propiedad industrial o de usurpación de nombre comercial. Por lo tanto, no son aplicaciones de competencia desleal en sentido estricto, sino de la protección mejorada aplicable a estos elementos de fondo.

3. Por otro lado, la falla consiste en la violación no de una norma legal (habría competencia prohibida) sino de un uso profesional (Corte de Casación francesa, 29 de abril de 1997). De ello resulta una doble dificultad. Desde un punto de vista práctico, es difícil conocer usos que a menudo no están codificados. De hecho, la codificación, al menos en esta área, enfrenta obstáculos casi insuperables, como lo demuestra el Código 
internacional de prácticas publicitarias leales (Code international des pratiques loyales en matière de publicité), adoptado por la Cámara de Comercio Internacional el 20 de mayo de 1973. En efecto este código presenta algunos detalles interesantes.

Art. 2. Décence. La communication commerciale doit proscrire toute déclaration ou tout traitement audio ou visuel contraire aux convenances selon les normes actuellement admises dans le pays et la culture concernés.

Art. 3 Loyauté. La communication commerciale doit être conçue de manière à ne pas abuser de la confiance des consommateurs ou à ne pas exploiter le manque d'expérience ou de connaissance des consommateurs.

Tout facteur pertinent susceptible d'influencer la décision des consommateurs doit être signalé d'une manière et à un moment qui permettent aux consommateurs de le prendre en considération.

Art. 4 Responsabilité sociale. La communication commerciale doit respecter la dignité humaine et ne doit encourager ou cautionner aucune forme de discrimination, y compris fondée sur la race, l'origine nationale, la religion, le sexe, l'âge, le handicap ou l'orientation sexuelle.

La communication commerciale, sauf raison justifiable, doit proscrire toute exploitation des sentiments de peur, de malchance ou de souffrance.

La communication commerciale ne doit pas sembler cautionner ou encourager des comportements violents, illicites ou antisociaux.

La communication commerciale doit proscrire toute exploitation de la superstition. (Code international des pratiques loyales en matière de publicité, adoptado por la Cámara de Comercio Internacional con fecha 20 de mayo de 1973, arts. 2 a 5)

Via Inveniendi Et Iudicandi

e-ISSN: 1909-0528 | DOI: https://doi.org/10.15332/19090528

Vol. 16 N. ${ }^{\circ} 1$ | enero-junio del 2021 
A menudo invoca la noción de lealtad, lo cual constituye una tautología (Guyon, 2003, p. 916) cuando se trata de definir competencia desleal. Desde un punto de vista teórico, la exclusiva referencia a los usos profesionales genera el riesgo de conducir a soluciones de tipo corporativo. Los comerciantes considerarán que la competencia que ellos practican es leal mientras que la competencia que experimentan no lo es. Sin embargo, la acción en competencia desleal no parece tener como único fundamento la protección exclusiva de otros comerciantes. También interesa a los acreedores y a los empleados de la empresa competidora, al sufrir las consecuencias de su ruina. Lamentablemente, estas diversas bases no siempre son conciliables.

4. Sin embargo, sí parece verificarse una mínima claridad conceptual, la falta oscila alrededor de la noción de deslealtad, a su turno inscrita en un contexto de antagonismo: la rivalidad entre comerciantes, si bien admitida por el sistema jurídico, tiene límites claros; estos observan como objetivo la defensa de la lealtad de la contienda, ya que en la guerra comercial todos los golpes no están autorizados. El derecho de hacer competencia es susceptible de abuso (Gual, 2009, p. 22). De ahí que la noción de lealtad contractual, reconociendo un natural antagonismo entre los contratantes, redimensione la noción de deslealtad contractual, al tiempo que legitima la aplicación de la teoría del abuso del derecho, así como la del abuso de posición contractual dominante. Un ejemplo de tal constatación es la sanción a la revocatoria abusiva de la oferta, al rechazo abusivo de una oferta, a las cláusulas abusivas, la fijación unilateral abusiva del precio o a la terminación unilateral abusiva del contrato. Estas figuras, desconocidas por el derecho tradicional de contratos, hallan su fundamento en el régimen de competencia mercantil y la manera en que caracteriza la deslealtad o el abuso. 
5. Fruto de las anteriores constataciones, la falta no necesita ser intencional. A fortiori no supone una intención de dañar (Corte de Casación francesa, 18 de abril de 1958; Corte de Casación francesa, 6 de noviembre de 1990; Corte de Casación francesa, 26 de abril de 1994). Además, y contrariamente a la ortodoxia de la teoría de la responsabilidad civil, los tribunales franceses tienden a condenar a daños mayores al que cometió una falta intencional, incluso si esta no causó un daño mayor al de una simple negligencia.

\section{Referencias}

Arnaud, A.-J. (2004). Entre modernité et mondialisation: leçons d'histoire de la philosophie du droit et de l'État (2. ${ }^{\mathrm{a}}$ ed.). LGDJ.

Arrubla, J. (2006). Contratos mercantiles: contratos atípicos (Tomo III). Legis.

Auguet, Y. (2000). Concurrence et clientèle: contribution à l'étude critique du rôle des limitations de concurrence pour la protection de la clientèle. LGDJ.

Auguet, Y. (2002). Droit de la concurrence. Ellipses.

Azéma, J. (1990). Le droit français de la concurrence (2. ${ }^{\mathrm{a}}$ edición). PUF.

Barret, O. (2005). Variations autour du refus de contracter. En Mélanges Jean-Luc Aubert: propos sur les obligations et quelques autres thèmes fondamentaux du droit (pp. 5-22). Dalloz.

Basedow, J. (1998). Un droit commun des contrats pour le marché commun. Revue Internationale de Droit Comparé, 5o(1), 7-28. https://www.persee.fr/doc/ridc 0035-3337 1998 num $50 \quad 1 \quad 1113$

Basedow, J. (1999). Vie universelle. Droit national? À propos de la mondialisation du droit. En Mélanges en l'honneur de Denis Tallon: D’ici, d'ailleurs: harmonisation et dynamique du droit (pp. 226-248). Société de Législation Comparée.

Bonassies, P. (1983). Les fondements du droit communautaire de la concurrence: la concurrence-moyen. En Études dédiées à Alex Weill (pp. 51-73). Dalloz-Litec.

Bonivento, J. (2017). Los principales contratos civiles y su paralelo con los mercantiles. Librería del Profesional.

Via Inveniendi Et Iudicandi

e-ISSN: 1909-0528 | DOI: https://doi.org/10.15332/19090528

Vol. 16 N.o 1 | enero-junio del 2021 
Boutard-Labarde, M.-C. y Canivet, G. (1994). Droit français de la concurrence. LGDJ.

Burst, J.-J. (1993). Concurrence déloyale et parasitisme. Dalloz.

Cañón, M., Echeverry, D. y Blanco, R. (2020). Promesas de compraventa como medio de reubicación de vendedores informales: procedencia de la venta directa de bienes fiscales del Estado. En D. A. Echeverry (ed.), Justicia o eficiencia en la asignación de los derechos de propiedad y las relaciones de intercambio: implicaciones negociales (pp. 127-151). Ediciones USTA.

Cely, A. (2011). Les fondements de la responsabilité civile des dirigeants des sociétés: étude franco-colombienne (tesis de doctorado, Université Paris II). https://docassas.u-París2.fr/nuxeo/site/esupversions/c8589e10-939d-4d88-aoecb6886ae78228?inline

Chagny, M. (2004). Droit de la concurrence et droit commun des obligations. LGDJ.

Champalaune, C. (2001). Le principe de la liberté du commerce et de l'industrie et la libre concurrence. Rapport Cour de cassation. Corte de Casación francesa.

https://www.courdecassation.fr/publications_26/rapport_annuel_36/rapport_20 o1 117/deuxieme partie tudes documents 120/tudes theme libertes 122/com merce industrie 5970.html

Champaud, C. (1985). Les sources du droit de la concurrence. Etudes offertes à Roger Houin: problèmes d'actualité posés par les entreprises (pp. 61-83). Dalloz-Sirey.

Champaud, C. (2002). Régulation et droit économique. Revue Internationale de Droit Économique, 16(1), 23-66.

Clamour, G. (2006). Intérêt général et concurrence: essai sur la pérennité du droit public en économie de marché. Dalloz.

Cortabarría, J. (2005). El Code Napoleón y sus comentaristas como fuentes del Código Civil argentino. Revista Iushistoria, 1, 1-14. https:/p3.usal.edu.ar/index.php/iushistoria/article/view/1644/2077

Cros, C. (2002). La clause de non concurrence accessoire au contrat de cession d'un bien immobilier. Recueil Dalloz, 11(7064), 908-929.

De Leyssac, C. L. y Parleani, G. (2002). Droit du marché. PUF.

Decocq, A. y Decocq, G. (2002). Droit de la concurrence interne et communautaire. LGDJ.

Via Inveniendi Et Iudicandi

e-ISSN: 1909-0528 | DOI: https://doi.org/10.15332/19090528

Vol. 16 N.o 1 | enero-junio del 2021 
Decocq, A. y Decocq, G. (2010). Droit européen des affaires. LGDJ.

Delmas-Marty, M. (2000). La pénalisation internationale des activités économiques: un espace à géographie variable. En É. Louquin y C. Kessedjian (dirs.), $L a$ mondialisation du droit (pp. 400-419). Litec.

Delmas-Marty, M. (2001). Les processus de mondialisation du droit. En C.-A. Morand (dir.), Le droit saisi par la mondialisation (pp. 63-80). Bruylant.

Dreifuss-Netter, F. (1990). Droit de la concurrence et droit commun des obligations. Revue trimestrielle de Droit Civil, 369-391.

Echeverry, D. L. y Díaz, S. (2016). Minería aurífera ilegal en el resguardo indígena alto Andágueda. Novum Jus, 1O(1), 135-149. https://doi.org/10.14718/NovumJus.2016.10.1.6

Emiliani, R. (2001). Curso razonado de las obligaciones, la obligación civil y sus fuentes voluntarias (Tomo I, Parte Primera). Editorial Universidad Sergio Arboleda.

Fages, B. y Mestre, J. (1998). L'emprise du droit de la concurrence sur le contrat. Revue trimestrielle de Droit Commercial, 71-81.

Farjat, G. (1963). L'ordre public économique. Dalloz.

Farjat, G. (2003). Propos critiques et utopiques sur l'évolution du droit économique et la mondialisation. Revue Internationale de Droit Économique, 17(3-4), 511-531.

Favoreu, L. (2014). Droit Constitutionnel. Dalloz.

Flour, J., Aubert, J.-L. y Savaux, E. (2012). Droit civil, les obligations (tomo 1). L'acte juridique (15. ${ }^{\mathrm{a}}$ ed.). Sirey.

Gallego, J. (2014). Paradoja y complejidad de los derechos humanos en la sociedad moderna. Sentido y comunicación. Revista IUSTA, 4O, 143-165. https://doi.org/10.15332/s1900-0448.2014.0040.01

Garat, M. (2018). El Gobierno, la Constitución y el orden económico, con particular referencia al marco constitucional uruguayo. Revista Estudios Constitucionales, 16(2), 307-338. http://dx.doi.org/10.4067/So718-52002018000200307

Via Inveniendi Et Iudicandi

e-ISSN: 1909-0528 | DOI: https://doi.org/10.15332/19090528

Vol. 16 N. ${ }^{0} 1$ | enero-junio del 2021 
Gauvain, R. (2019). Rétablir la souveraineté de la France et de l'Europe et protéger nos entreprises des lois et mesures à portée extraterritorial: Rapport à la demande de Monsieur Édouard Philippe Premier Ministre par Député de Saône-et-Loire Parlementaire en mission (LO144). https://www.viepublique.fr/sites/default/files/rapport/pdf/194000532.pdf

Ghestin, J. (1981). L'utile et le juste dans les contrats. Archives de Philosophie du Droit, $26,57-75$.

Ghestin, J. (1984). L'ordre public, notion à contenu variable en droit privé français. En C. Perelman y R. Van Der Elst (dirs.), Les notions à contenu variable en droit (pp. 7793). Centre national de recherches de logique.

Goldman, B. (1992). La liberté du commerce dans les pays développés. G. Farjat y B. Remiche (dirs.), Liberté et droit économique (pp. 95-112). De Boeck.

Gual, J. (2009). El control de las cláusulas abusivas. Un régimen en evolución. Revista IUSTA, 30, 15-44. https://doi.org/10.15332/s1900-0448.2009.0030.01

Guyon, Y. (1978). Que reste-t-il du principe de la liberté du commerce et de l'industrie? En J. M. Mousseron y B. Teyssie (dirs.), Dix ans de droit de l'entreprise (pp. 5-27). Librairies techniques.

Guyon, Y. (1995). Développer la concurrence. Cahier de Droit de L'entreprise, 2, 19-41.

Guyon, Y. (2000). Traité des contrats. Les sociétés (aménagements statutaires et conventions entre associés) ( $4 \cdot^{\mathrm{a}} \mathrm{ed}$.). LGDJ.

Guyon, Y. (2003). Droit des affaires: droit commercial général et sociétés (T. 1). Economica.

Guzmán, A. (1994). El código Napoleón y el Código Civil de Chile. Boletín de la Academia Nacional de Derecho y Ciencias Sociales de Córdoba, 1o, 1361-1383.

Guzmán, A. (2000). La codificación civil en Iberoamérica, siglos XIX y XX. Editorial Jurídica de Chile.

Guzmán, A. (2009). Estudios de historia dogmática y sistémica sobre el código civil chileno-colombiano. Pontificia Universidad Javeriana.

Hémard, J. (1950). L'économie dirigée et les contrats commerciaux. En Le droit privé français au milieu du XX $X^{e}$ siècle : études offertes à Georges Ripert. Tome II, La propriété, contrats et obligations, la vie économique. (pp. 341-363). LGDJ.

Via Inveniendi Et Iudicandi

e-ISSN: 1909-0528 | DOI: https://doi.org/10.15332/19090528

Vol. 16 N.o 1 | enero-junio del 2021 
Hourquebie, F. (2012a). Diversité des cultures juridiques: comment relever les défis de la mondialisation? En Organisation internationale de la Francophonie, Rapport sur l'état des pratiques de la démocratie, des droits et des libertés dans l'espace francophone (pp. 88-99). Délégation à la paix, à la démocratie et aux droits de l'homme.

Hourquebie, F. (2012b). Le principe d'indépendance de la justice dans les pays de l'espace francophone. Les Cahiers de la justice, 2, 41-60.

Jamin, C. (dir.). (2008). Droit et économie des contrats. LGDJ.

Jiménez, F. (2015). Teoría del contrato y del negocio jurídico. Legis.

Kdhir, M. (1994). Le principe de la liberté du commerce et de l'industrie: mythe ou réalité. Recueil Dalloz, 4, 30-43.

Larroumet, C. (dir.). (2004). L'avenir de la codification en France et en Amérique Latine. Actes du colloque international organisé par l'Association Andrés Bello des juristes franco-latino-américains. Association Andrés Bello des juristes francolatino-américains.

Le Quinio, A. (2011). Recherche sur la circulation des solutions juridiques: le recours au droit comparé par les juridictions constitutionnelles. Fondation Varenne.

Le Tourneau, P. (1994). La concession commerciale exclusive. Economica.

Malaurie, P. (1953). L'ordre public et le contrat, étude de droit civil comparé France, Angleterre, URSS. Matot-Braine.

Malaurie-Vignal, M. (1995). Droit de la concurrence et droit des contrats. Recueil Dalloz, $8,51-54$.

Malaurie-Vignal, M. (1996). Droit interne de la concurrence. Armand Colin.

Marque, J. N. (1967). G. Farjat, L'ordre public économique. Revue Internationale de Droit Comparé, 19(2), 520. https://www.persee.fr/doc/ridc 0035$3337 \quad 1967$ num $19 \_2 \quad 14861$

Maymon-Goutaloy, M. (1982). Contre une intervention législative en matière de concession commerciale. Revue trimestrielle de Droit Commercial, 35(4), 520-534.

Mestre, J. (1987). obs. Revue trimestrielle de Droit Civil, 304-316.

Mestre, J. (1994). obs. Revue trimestrielle de Droit Civil, 349-361.

Via Inveniendi Et Iudicandi

e-ISSN: 1909-0528 | DOI: https://doi.org/10.15332/19090528

Vol. 16 N. ${ }^{\circ} 1$ | enero-junio del 2021 
Mestre, J. (1996). L’ordre public dans les relations économiques. En T. Revet (dir.), L'ordre public à la fin du XX $X^{e}$ siècle (pp. 33 y ss.). Dalloz.

Mirow, M. (2000). The power of codification in Latin America. Simón Bolívar and the Code Napoleon. Tulane Journal of International and Comparative Law, 8, 83-116. https://ecollections.law.fiu.edu/faculty_publications/121

Mockle, D. (2002). Mondialisation, droit des peuples et État de droit. En D. Mockle, (dir.), Mondialisation et Etat de droit (pp. 237-288). Bruylant.

Oppetit, B. (1992). Droit et économie. Archives de philosophie du droit, 37, 17-26.

Oppetit, B. (1995). La liberté contractuelle à l'épreuve du droit de la concurrence. Revue des sciences morales et politiques, 241-254.

Ospina, G. y Ospina, E. (2018). Teoría general del contrato y del negocio jurídico. Temis.

Pédamon, M. (1983). La liberté d'entreprendre et l'intervention des autorités publiques, dans les autorités publiques et l'entreprise privée. Revue de Jurisprudence Commerciale (número especial), 13-25.

Pfister, L. (2012). Contrat, libre concurrence et ordre public: la sanction des ententes dans la jurisprudence française du XIX ${ }^{\mathrm{e}}$ siècle. Revue des Contrats, 2, 349-361.

Pimont, S. (2004). L'économie du contrat. PUAM.

Pollaud-Dulian, F. (1999). Droit de la propriété industrielle. Montchrestien.

Quiroz, M. (2014). Acercamiento a las “oposiciones paradigmáticas” entre neoconstitucionalismo y positivismo jurídico en Revista IUSTA, 2(41), 77-97. https://www.redalyc.org/articulo.oa?id=560358701004

Ramos, C. (1997). El Código napoleónico y su recepción en América Latina. Universidad Católica del Perú.

Rengifo, E. (2004). Del abuso del derecho al abuso de la posición dominante. Universidad Externado de Colombia.

Revet, T. (coord.). (1996). L'ordre public à la fin du XX'e siècle. Dalloz.

Ripert, G. (1934). L'ordre économique et la liberté contractuelle. Recueil d'études sur les sources du droit en l'honneur de François Gény: les sources generales des systemes juridiques actuels. (pp. 347-359) (t. II). Sirey.

Via Inveniendi Et Iudicandi

e-ISSN: 1909-0528 | DOI: https://doi.org/10.15332/19090528

Vol. 16 N. ${ }^{\circ} 1$ | enero-junio del 2021 
Robichez, J. (1999). Droit du travail, droit de la concurrence et droit de la consommation, le rôle de la branche du droit dans la didactique juridique (tesis de doctorado, Université Paris I). http://www.theses.fr/1999PA010255

Ruet, L. (2002). Du principe de rivalité. Recueil Dalloz, 3086-3099.

Saidiza, H. y Carvajal, J. (2016). Crisis del Estado de derecho en Colombia: un análisis desde la perspectiva de la legislación penal. Revista IUSTA, 44, 17-39. https://doi.org/10.15332/s1900-0448.2016.0044.01

Salah, M. (1999). Les transformations de l'ordre public économique, vers un ordre public régulatoire. Philosophie du droit et droit économique quel dialogue?Mélanges en l'honneur de Gérard Farjat(pp. 264-276). Frison-Roche.

Savatier, R. (1965). L’ordre publique économique. Recueil Dalloz, 31-43.

Schaeffer, E. (1981). L’abus dans le droit de la concurrence. Gazette du Palais, 401-418.

Schmidt-Szalewski, J. (2003). Développement de l'action en concurrence déloyale. Mélanges en l'honneur de Yves Guyon: aspects actuels du droit des affaires (pp. 933-947). Dalloz.

Serna, J.-C. (1967). Le refus de contracter. LGDJ.

Serra, Y. (1998). Les fondements et le régime de l'obligation de non-concurrence. Revue trimestrielle de Droit Commercial, 51, 7-22.

Stoffel-Munck, P. (2000). L’abus dans le contrat, essai d’une théorie. LGDJ.

Terré, F., Simler, P. Lequette, Y., Chénedé, F. (2013). Droit civil. Les obligations. Dalloz.

Ullrich, H. (2003). La mondialisation du droit économique: vers un nouvel ordre public économique (Rapport introductif). Revue Internationale de Droit Économique, 17(3-4), 291-312. https://doi.org/10.3917/ride.173.0291

Vargas, A. (2018). Los límites y las consecuencias reales del discurso jurídico de la autonomía privada de la voluntad en el individuo. Revista IUSTA, 2(49), 91-114.

Vogel, L. (1994). Les limites du marché comme instrument du droit de la concurrence. Juris-classeur périodique - La Semaine Juridique I, 3737-3749.

Vogel, L. (1998). Droit de la concurrence et concentration économique, études comparatives. Economica.

Via Inveniendi Et Iudicandi

e-ISSN: 1909-0528 | DOI: https://doi.org/10.15332/19090528

Vol. 16 N. ${ }^{0} 1$ | enero-junio del 2021 


\section{Normas jurídicas citadas}

Cámara de Comercio Internacional. Code international des pratiques loyales en matière de publicité. 20 de mayo de 1973.

https://www.arpp.org/IMG/pdf/code_consolide_pratique_publicite_marketing.p df

Constitución Política de Colombia [C. P.]. 4 de julio de 1991 (Colom.).

Francia. Code de commerce. 1807.

Francia. Code pénal. 1810.

Francia. Décret 53-707. Relatif au contrôle de l'Etat sur les entreprises publiques nationales et certains organismes ayant un objet d'ordre économique ou social. 9 de agosto de 1953 . https://www.legifrance.gouv.fr/loda/id/JORFTEXToooooo299254/

Francia. Décret 91-1197. Organisant la profession d'avocat. 27 de noviembre de 1991. https://www.legifrance.gouv.fr/loda/id/JORFTEXTooooo0356568/

Francia. Loi 2001-420. Relative aux nouvelles régulations économiques. 15 de mayo de 2001. https://www.legifrance.gouv.fr/loda/id/JORFTEXTo00000223114/

Francia. Loi 2008-776. De modernisation de l'économie. 4 de agosto de 2008. Journal officiel, 0181 del 5 de agosto de 2008. https://www.legifrance.gouv.fr/jorf/jo/2008/08/07/0181

Francia. Loi 73-1193. D'orientation du commerce et de l'artisanat. 27 de diciembre de 1973. https://www.legifrance.gouv.fr/loda/id/JORFTEXTo00000509757/

Francia. Loi 87-499. Transférant le contentieux des décisions de l’Autorité de la concurrence à la juridiction judiciaire. 6 de julio de 1987 . https://www.legifrance.gouv.fr/loda/id/JORFTEXTo00000508810/

Francia. Loi 96-588. Sur la loyauté et l'équilibre des relations commerciales. 1 de julio de 1996.

Francia. Ordonnance 45-1483. Relative aux règles applicables en matière de prix. 8 de septiembre de 1945. (Derogada por la Ordonnance 86-1243 del 1 de diciembre de 1986).

Via Inveniendi Et Iudicandi

e-ISSN: 1909-0528 | DOI: https://doi.org/10.15332/19090528

Vol. 16 N.o 1 | enero-junio del 2021 
Francia. Ordonnance 86-1243. Relative à la liberté des prix et de la concurrence. 1 de diciembre de 1986.

https://www.legifrance.gouv.fr/loda/id/JORFTEXTo0o000333548/

Francia. Ordonnance 2019-359. Portant refonte du titre IV du livre IV du code de commerce relatif à la transparence, aux pratiques restrictives de concurrence et aux autres pratiques, prohibées. 24 de abril de 2019. Journal officiel, 0097, 25 de abril de 2019. https://www.legifrance.gouv.fr/loda/id/JORFTEXTo00038410002/

Unión Europea. Reglamento (CE) 1/2003. Del Consejo de la Unión Europea relativo a la aplicación de las normas sobre competencia previstas en los artículos 81 y 82 del Tratado Constitutivo de la Comunidad Europea, y en particular su artículo 83. 16 de diciembre de 2002. Diario Oficial n. ${ }^{\circ} \mathrm{L}$ o01 del 04 de enero de 2003. https://eur-lex.europa.eu/legal-content/ES/TXT/?uri=celex\%3A32003Rooo1

\section{Jurisprudencia citada (ordenada cronológicamente)}

Corte de Casación francesa, Sala de Mociones, Sentencia de 28 de febrero de 1865.

Corte de Casación francesa, Sala de Mociones, Champagne Heidsieck c. Charles

Heidsieck, Sentencia de 3 de febrero de 1909.

Corte de Casación francesa, Sala Comercial, Cognac Martell c. Charles Martel, Sentencia de 7 de diciembre de 1954 .

Corte de Casación francesa, Sala Comercial, Sentencia de 18 de abril de 1958.

Corte de Casación francesa, Sala Comercial, La Vache qui rit c. La Vache sérieuse, Sentencia de 5 de enero de 1966.

Corte de Casación francesa, Sala Social, Sentencia de 8 de mayo de 1967.

Corte de Casación francesa, Sala Comercial, Sentencia de 16 de octubre de 1972.

Corte de Casación francesa, Tercera Sala Civil, Sentencia de 16 de marzo de 1976. Recueil Dalloz, 1976, 559.

Corte de Casación francesa, Sala Comercial, Sentencia de 19 de julio de 1976. Bulletin Civil de la Cour de Cassation IV, 237, 203.

Corte de Casación francesa, Sala Comercial, Sentencia de 17 de abril de 1980. Bulletin Civil de la Cour de Cassation IV, 145, 113. 
Corte de Casación francesa, Sala Comercial, Sentencia de 28 de abril de 1980. Jurisclasseur périodique - La Semaine Juridique 1982, II, 19791.

Corte de Casación francesa, Sala Comercial, Sentencia de 27 de octubre de 1981. Bulletin Civil de la Cour de Cassation IV, 371, 295.

Corte de Casación francesa, Sala Comercial, Sentencia de 5 de octubre de 1982. Bulletin Civil de la Cour de Cassation IV, 296, 254.

Corte de Casación francesa, Sala Comercial, Sentencia de 15 de junio de 1983. Bulletin Civil de la Cour de Cassation IV, 174, 151.

Corte de Casación francesa, Sala Comercial, Sentencia de 30 de noviembre de 1983. Bulletin Civil de la Cour de Cassation IV, 331, 287.

Corte de Casación francesa, Sala Social, Sentencia de 27 de junio de 1984. Bulletin Civil de la Cour de Cassation V, 269, 204.

Corte de Casación francesa, Sala Comercial, Sentencia de 3 de enero de 1985. Bulletin Civil de la Cour de Cassation IV, 93, 82.

Corte de Casación francesa, Sala Comercial, Sentencia de 14 de mayo de 1985. Bulletin Civil de la Cour de Cassation IV, 148, 126.

Corte de Casación francesa, Sala Comercial, Sentencia de 22 de octubre de 1985. Bulletin Civil de la Cour de Cassation IV, 245, 206.

Corte de Casación francesa, Sala Comercial, Sentencia de 11 de octubre de 1988. Jurisclasseur périodique - La Semaine Juridique 1989, II, 21297, note Charley Hannoun y Xavier Desjeux.

Corte de Casación francesa, Sala Comercial, Sentencia de 29 de marzo de 1989. Recueil Dalloz, 1989, 408, note Yves Serra.

Tribunal de París, Révillon c. Carole Révillon, Sentencia de 11 de octubre de 1990. Revue des sociétés, 1991, 393.

Corte de Casación francesa, Sala Comercial, Sentencia de 6 de noviembre de 1990. Bulletin Civil de la Cour de Cassation IV, 262, 183.

Corte de Casación francesa, Sala Comercial, Sentencia de 18 de febrero y 26 de mayo de 1992. Recueil Dalloz, 1993, 57-59, note Charley Hannoun. 
Corte de Casación francesa, Sala Comercial, Sentencia de 14 de abril de 1992. Revue trimestrielle de Droit Commercial, 1992, 786, note Jean Derruppé; Revue trimestrielle de Droit Civil, 1993, 150, note Pierre-Yves Gautier.

Corte de Casación francesa, Sala Comercial, 26 de mayo de 1992. Recueil Dalloz, 1993, 57-59, note Charley Hannoun.

Corte de Casación francesa, Sala Comercial, Sentencia de 4 de mayo de 1993. Jurisclasseur périodique - La Semaine Juridique 1993, II, 22111, note Marie-Chantal Boutard-Labarde.

Corte de Casación francesa, Sala Comercial, Sentencia de 18 de mayo de 1993. Jurisclasseur périodique - La Semaine Juridique 1994, II, 22243, note Alain Dekeuwer.

Corte de Casación francesa, Sala Comercial, Sentencia de 4 de enero de 1994. Recueil Dalloz, 1995, 205, note Yves Serra.

Corte de Casación francesa, Sala Comercial, Sentencia de 26 de abril de 1994. Bulletin Civil de la Cour de Cassation IV, 151, 119.

Corte de Casación francesa, Sala Comercial, Sentencia de 18 de junio de 1996. Bulletin Civil de la Cour de Cassation IV, 185, 159.

Corte de Casación francesa, Sala Comercial, Sentencia de 29 de abril de 1997. Recueil Dalloz, 1997, 459, note Yves Serra. Revue trimestrielle de Droit Civil, 1998, 218, note Rémy Libchaber.

Corte de Casación francesa, Sala Comercial, Sentencia de 13 de mayo de 1997. Jurisclasseur périodique édition Entreprises, 1998, 79, note Jean Pierre Fourgoux.

Corte Constitucional colombiana. Sentencia T-375, 14 de agosto de 1997. https://www.corteconstitucional.gov.co/relatoria/1997/t-37597.htm\#: :text=T\%2D375\%2D97\%20Corte\%20Constitucional\%20de\%20Colombi a\&text=La\%2oposici\%C3\%B3n\%2odominante\%20se\%2orefiere,grado\%2orelativa mente\%20amplio\%20y\%20apreciable

Corte de Casación francesa, Sala Comercial, Sentencia de 1 de junio de 1999. Bulletin Civil de la Cour de Cassation IV, 114, 93.

Corte de Casación francesa, Sala Comercial, Sentencia de 19 de noviembre de 2002. Bulletin Civil de la Cour de Cassation IV, 171, 196. 
Consejo de Estado francés, Assemblée plénière, Ordre des avocats au barreau de Paris, Sentencia 275531 de 31 de mayo de 2006.

Corte Constitucional colombiana. Sentencia C-228, 24 de marzo de 2010. https://www.corteconstitucional.gov.co/relatoria/2010/c-228-10.htm

Consejo Constitucional francés, Sentencia 771 DC, de 25 de octubre de 2018.

Tribunal de Douai, Sentencia de 2 de octubre de 1995. Recueil Dalloz, 1996, 99, note Jean Pierre Fourgoux.

Tribunal de Gran Instancia de Grenoble, Sentencia de 3 de mayo de 1984. Gazette du Palais, 372. 